\title{
Development of Modified QuEChERS Methodology Coupled with RP-HPLC for Quantification of Various Insecticides in Rice Grains
}

\author{
Romila Akoijam $^{1 *}$, Arati Ningombam ${ }^{1}$, Aruna Beemrote ${ }^{1}$ and R.S. Telem ${ }^{2}$ \\ ${ }^{1}$ ICAR Research Complex for North Eastern Hill region, Manipur Centre, Lamphelpat, India \\ ${ }^{2}$ KVK, Hengbung, Senapati, India \\ *Corresponding author
}

K e y w o r d s
Imidacloprid, Carbofuran,
Rice grains, HPLC
Article Info
Accepted:
22 October 2018
Available Online:
10 November 2018

A B S T R A C T
A method of reverse phase-high performance liquid chromatography (HPLC) was standardized and developed coupled with modified UV-VIS detection system was standardized for simultaneous determination of residues of imidacloprid, carbofuran, chlorantraniliprole, fipronil, malathion, chloropyriphos and cypermethrin in rice grains. Extraction and clean-up process was done by modified QuEChERS method. The Brownlee Analytical C18 column was used for separation with an isocratic flow @ $0.5 \mathrm{~mL} \mathrm{~min}$ of $^{-1}$ mobile phase of acetonitrile and water $(90: 10$, v/v) was operated. The peaks of imidacloprid, carbofuran, chlorantraniliprole, fipronil, malathion, chloropyriphos and Cypermethrin A, B and C in chromatograms depicted at retention times of $2.67 \mathrm{~min}, 3.25$ min, $3.54 \mathrm{~min}, 3.93 \mathrm{~min}, 4.08 \mathrm{~min}, 8.19 \mathrm{~min}$ and 9.32, 9.78 and $10.00 \mathrm{mins}$ respectively. Constant recoveries were observed above $80 \%$ for all the three insecticides when samples were fortified at different levels of $0.05,0.10,0.25,0.50$ and $1.00 \mathrm{mg} \mathrm{kg}^{-1}$ levels.

\section{Introduction}

Being India secured second position in production and consumption of rice in the world next after China. Rice cultivation requires good irrigation facility or heavy annual rainfall. It suits on rainfed areas with hot and humid climate (Barrion et al., 2007). Rice production is mainly affected by various abiotic and biotic factors, which ultimately led to the decline in yield (Behura et al., 2011). Biotic factors include various insect pests which caused significant damage and crop losses. Major biotic factors that influence rice production in the northeastern hills are diseases, insect pests, rodents and weeds.
More than 100 insect species are known to attack the rice crop of which 20 species are considered highly important that results in economic damage (Arora and Dhaliwal, 1996). In Manipur, among the pyralid pests, the leaf folder, yellow stem borer plays a major role in reduction of yield (Barwal et al., 1994).

Starting from early germination to crop maturity stage, around ten species of insects like Gall midge (Orseolia oryzae Wood Mason), Yellow stem borer (Scirpophaga incertulas Walker), Leaf folder (Cnaphalocrocis medinalis Guenee) Rice case worm (Nymphula depunctalis Guenee), Rice whorl maggot (Hyderellia philippina Ferina), 
Small grasshopper (Oxya chinensis Walker), Green leaf hopper (Nephotettix virescens Distant), Rice gundhi bug (Leptocorisa acuta Thunb), Tobacco caterpillar (Spodoptera mauritia Boisd) and Rice army worm (Mythima seperata Walker) were reported to be the most important and regular pest of this crop in Manipur. Different species of stem borer (S. incertulas, $C$. suppressalis and Sesamia inferens), Gall midge (Oreseolia oryzae), leaf folder (C. medinalis), case worm (N. depunctalis) and plant hoppers (Nilaparvata lugens and Sogatella furcifera) are the major pests causing severe damage to rice crops (Jenita et al., 2016). Farmers use various groups of insecticides to combat the damage caused by insect pests. Most of the farmers use insecticides like monocrotophos, dichlorvos, malathion, chloropyriphos, Cypermethrin, deltamethrin, thiamethoxam, Imidacloprid, carbofuran, chlorantraniliprole, flubendiamide, fipronil, etc. Ideally a pesticide must be lethal to the targeted pests only, but not to non-target species, including human being. Unluckily, this is not happened, so the storm of use and abuse of pesticides has risen up. Pesticides can contaminate soil, water, turf, and other vegetation. Once the pesticides have applied, they can harm plants and animals ranging from beneficial soil microorganisms and insects, non-target plants, fish, birds, and other wildlife (Aktar et al., 2009). There are no informations available on the nature and quantity of pharmacologically active compounds of different insecticides in rice which is necessary to ensure the safety of the consumers and the environment. Therefore, the method was developed for the estimation of various insecticides in rice.

\section{Materials and Methods}

The experiment was conducted at Indian Council of Agricultural Research-Research Complex for North Eastern Hill region Manipur Centre, Lamphelpat, India.
The technical grade analytical standards such as Imidacloprid $(99.9 \%)$, carbofuran $(98.0 \%)$, chlorantraniliprole (99.20\%), fipronil $(97.5 \%)$, malathion (98.0\%), chloropyriphos $(98.0 \%)$ and cypermethrin (94.3\%) and primary secondary amine (PSA) sorbent were procured from sigma-aldrich, Kolkatta (Fig. 1). Chemicals such as sodium chloride, activated anhydrous magnesium sulphate $\left(\mathrm{MgSO}_{4}\right)$, anhydrous sodium sulfate and solvents like high-performance liquid chromatography (HPLC) grade acetonitrile, HPLC grade water were obtained from E. Merck (India) Ltd, Mumbai, India. All the solvents used were of laboratory grade and were redistilled in all glass apparatuses before experiment. The suitability of the solvents and other chemicals was ensured by running reagent blanks before real analysis.

The high-performance liquid chromatograph (series 200) was equipped with a reversephase, RP, C18 column and a UV-VIS detector, and dual pumps supplied by M/S Perkin Elmer, United States. The HPLC column, a Brownlee Analytical C18 column (150 $\mathrm{mm}$ column length, $4.6 \mathrm{~mm}$ inside diameter and $5 \mu \mathrm{m}$ particle size) was also procured from M/S Perkin Elmer. For the control of instrument, data acquisition and processing, TC Nav software was used. A good satisfactory separation of peak symmetry was obtained with an isocratic mobile phase comprising of acetonitrile: water (90: 10, v/v) at a flow rate of $0.5 \mathrm{~mL} / \mathrm{min}$. Quantification was achieved with UV-VIS detection at 225 $\mathrm{nm}$ based on peak area with a retention factor of $10 \mathrm{~min}$ and injection volume of $20 \mu \mathrm{L}$.

A standard stock solution of thiamethoxam, flubendiamide and endosulphan $(1 \mathrm{mg} / \mathrm{mL})$ was prepared in HPLC grade acetonitrile. For the construction of a calibration curve (2.00, $5.00,10.00,15.00$ and $20.00 \mathrm{mg} / \mathrm{mL}$ ) the standard solutions required were prepared from stock solution by serial dilution with 
HPLC grade acetonitrile. All standard solutions were stored at $4^{\circ} \mathrm{C}$ before experiment.

Rice grains were used as substrates for standardization of the methodology proposed for estimation of imidacloprid, carbofuran, chlorantraniliprole, fipronil, malathion, chloropyriphos and cypermethrin. Rice grains treated to be control samples were collected from hill-top Senapati district (Manipur) without any history of application of pesticides. The rice grains samples were fortified at different levels, i.e., 0.05, 0.10, $0.25,0.50$ and $1.00 \mathrm{mg} / \mathrm{kg}$. There were five replications for each treatment.

The quick easy cheap effective rugged and safe (QuEChERS) method was modified by taking a representative sample of $15 \mathrm{~g}$ of rice grains was weighed into a $50 \mathrm{~mL}$ centrifuge tube. After that $30 \mathrm{~mL}$ of acetonitrile was poured into all the centrifuge tubes. The samples were vigorously shaken and homogenized at 15,000 rpm for 2-3 min using a Heidolph homogenizer. Sodium chloride (10 g) was added to each sample and shaken dynamically by rotospin for around $5 \mathrm{~min}$. The samples were centrifuged using a laboratory centrifuge for $3 \mathrm{~min}$ at $5500 \mathrm{rpm}$.

The top $15 \mathrm{~mL}$ organic layer from each of the $15 \mathrm{~mL}$ tube was decanted into another $50 \mathrm{~mL}$ centrifuge tube which was weighed with $10 \mathrm{~g}$ of activated sodium sulfate. It was again shaken using a rotospin for $2 \mathrm{~min}$. The sample extract $(6 \mathrm{~mL})$ was transferred to a $15 \mathrm{~mL}$ centrifuge tube containing PSA sorbent (150 $\mathrm{mg}$ ) and activated anhydrous magnesium sulfate $(900 \mathrm{mg})$. The tube was tightly capped and vortexed for $30 \mathrm{~s}$. The tubes were centrifuged for $3 \mathrm{~min}$ at $2,500 \mathrm{rpm}$. The top extract $(4 \mathrm{~mL})$ was transferred into a test tube and concentrated to $2 \mathrm{~mL}$ with a rotary evaporator under $35^{\circ} \mathrm{C}$ for further quantification by HPLC.

\section{Results and Discussion}

Reversed-phase HPLC, with UV-VIS detection, was shown to be good for determination of imidacloprid, carbofuran, chlorantraniliprole, fipronil, malathion, chloropyriphos and cypermethrin because no need for derivatization step. Chromatographic separation in $\mathrm{C} 18$ columns provides good outcome. The detection at $225 \mathrm{~nm}$ provides suitable chromatograms for the quantification of imidacloprid, carbofuran, chlorantraniliprole, fipronil, malathion, chloropyriphos and cypermethrin in real samples. Under the preferred conditions, imidacloprid, carbofuran, chlorantraniliprole, fipronil, malathion, chloropyriphos and cypermethrin showed retention factors of 2.67 min, $3.25 \mathrm{~min}, 3.54 \mathrm{~min}, 3.93 \mathrm{~min}, 4.08 \mathrm{~min}$, $8.19 \mathrm{~min}$ and $8.19 \mathrm{~min}$ respectively (Fig. 2).

The fortified samples of rice grains at different levels were found to be in the range of 82.12 to $95.74 \%$ for imidacloprid, 87.09 to 93.18 for carbofuran, 80.25 to $90.18 \%$ fopr chlorantraniliprole, 80.87 to $97.72 \%$ for fipronil, 84.56 to $90.14 \%$ for malathion, 86.12 to $97.43 \%$ chloropyriphos and 85.90 to 87.78 $\%$ for cypermethrin A, cypermethrin B and cypermethrin c were found to be in the range of 82.18 to $88.34 \%, 80.90$ to $91.95 \%, 82.24$ to $98.27 \%$ and 86.71 to $97.80 \%$ respectively (Table 1). A specific, simplified, quick, costeffective reversed-phase HPLC method by using QuEChERS has been developed for the determination of imidacloprid, carbofuran, chlorantraniliprole, fipronil, malathion, chloropyriphos and cypermethrin. The consistent recoveries ranging from 80.25 to $97.79 \%$ for all the insecticides were observed when samples were fortified at $0.05,0.10$, $0.25,0.50$ and $1.00 \mathrm{mg} / \mathrm{kg}$ levels. The present QuEChERS method is quite effective and provides the quickest, easy and cheap method as compared with that of the traditional methods. 
Fig.1 Chemical structure of (a) imidacloprid, (b) carbofuran, (c) chlorantraniliprole, (d) fipronil, (e) malathion, (f) chloropyriphos and (g) cypermethrin

(a) Imidacloprid<smiles>CNC(=O)c1cc(Cl)cc(C)c1NC(=O)c1cc(Br)nn1-c1ncccc1Cl</smiles>

(c) Chlorantraniliprole<smiles>CCOC(=O)CC(SP(=S)(OC)OC)C(=O)OCC</smiles>

(e) Malathion<smiles>CNC(=O)Oc1cccc2c1OC(C)(C)C2</smiles>

(b) Carbofuran<smiles>N#Cc1nn(-c2c(Cl)cc(C(F)(F)F)cc2Cl)c(N)c1S(=O)C(F)(F)F</smiles>

(d) Fipronil<smiles>CCOP(=S)(OCC)Oc1nc(Cl)c(Cl)cc1Cl</smiles>

(f) Chloropyriphos

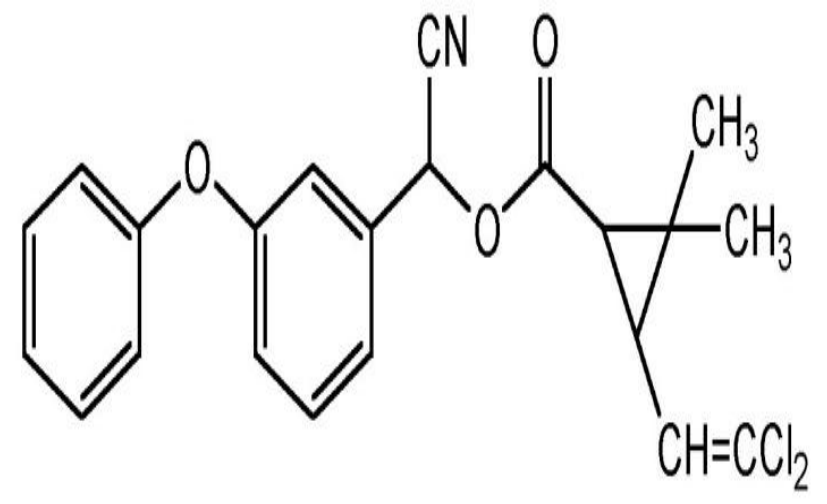

(g) Cypermethrin 
Table.1 Recovery (\%) of imidacloprid, carbofuran, chlorantraniliprole, fipronil, malathion, chloropyriphos and cypermethrin A, cypermethrin $B$ and cypermethrin $C$ in rice grains $(n=5)$

\begin{tabular}{|c|c|c|c|c|c|c|c|c|c|}
\hline $\begin{array}{l}\text { Level of } \\
\text { fortification } \\
\left(\mathrm{mg} \mathrm{kg} \mathbf{~}^{-1}\right)\end{array}$ & Imidacloprid & Carbofuran & Chlorantraniliprole & Fipronil & Malathion & Chloropyrifos & $\begin{array}{c}\text { Cypermethrin } \\
\text { A }\end{array}$ & $\begin{array}{c}\text { Cypermethrin } \\
\text { B }\end{array}$ & $\begin{array}{c}\text { Cypermethrin } \\
\text { C }\end{array}$ \\
\hline 0.05 & $82.12 \pm 2.34$ & $87.09 \pm 3.02$ & $89.76 \pm 1.08$ & $95.87 \pm 3.00$ & $87.89 \pm 0.67$ & $95.76 \pm 1.43$ & $87.78 \pm 2.35$ & $90.25 \pm 2.65$ & $90.25 \pm 2.80$ \\
\hline 0.10 & $93.05 \pm 1.92$ & $93.18 \pm 1.24$ & $90.18 \pm 3.01$ & $94.13 \pm 1.94$ & $86.44 \pm 2.20$ & $86.12 \pm 3.25$ & $87.49 \pm 1.01$ & $85.07 \pm 3.08$ & $90.60 \pm 2.31$ \\
\hline 0.25 & $86.35 \pm 3.80$ & $90.12 \pm 2.78$ & $80.25 \pm 1.67$ & $80.87 \pm 3.89$ & $90.14 \pm 1.90$ & $97.43 \pm 0.65$ & $87.14 \pm 3.06$ & $91.10 \pm 1.09$ & $81.15 \pm 3.08$ \\
\hline 0.50 & $92.12 \pm 1.03$ & $87.76 \pm 2.67$ & $86.55 \pm 3.93$ & $84.00 \pm 3.04$ & $84.56 \pm 4.67$ & $95.10 \pm 1.37$ & $87.65 \pm 2.09$ & $91.11 \pm 2.00$ & $93.34 \pm 2.13$ \\
\hline 1.00 & $95.74 \pm 2.22$ & $87.70 \pm 2.02$ & $89.90 \pm 1.08$ & $97.72 \pm 1.98$ & $87.25 \pm 2.82$ & $95.24 \pm 2.79$ & $85.90 \pm 1.68$ & $90.55 \pm 3.02$ & $97.79 \pm 2.23$ \\
\hline
\end{tabular}


Fig.2 HPLC chromatograms of standards of imidacloprid, carbofuran, chlorantraniliprole, fipronil, malathion, chloropyriphos and cypermethrin $\mathrm{A}$, cypermethrin $\mathrm{B}$ and cypermethrin $\mathrm{C}$ in which retention times on $\mathrm{x}$-axis and \% deflection on $\mathrm{y}$-axis

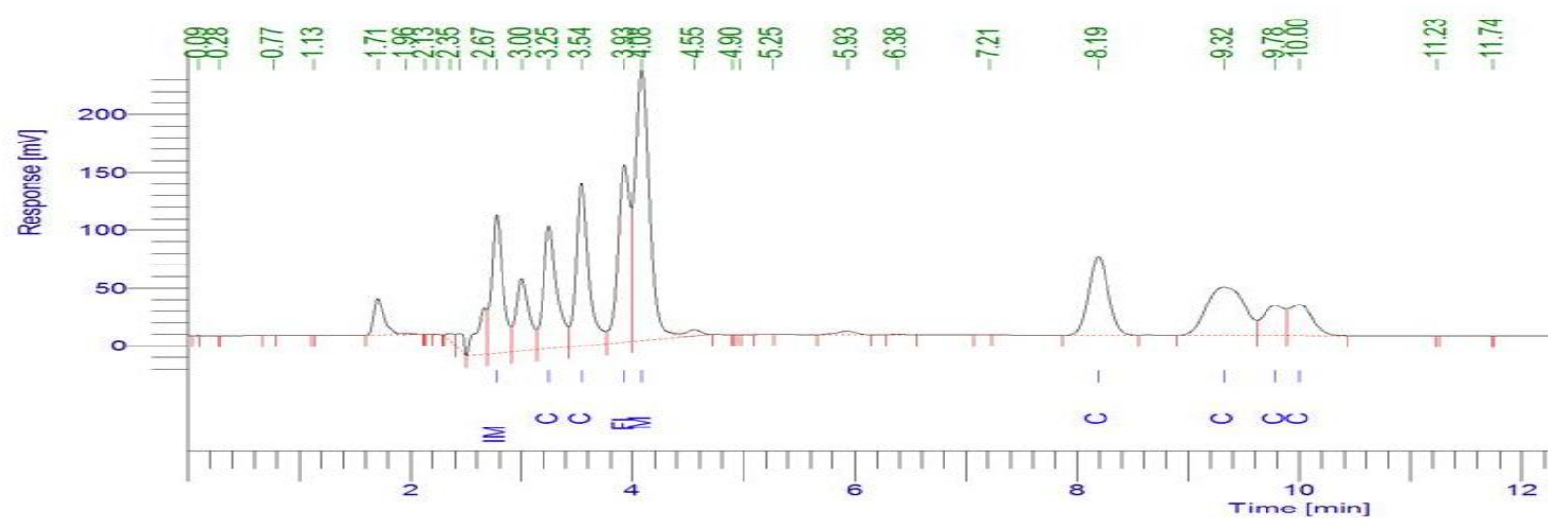

\section{Acknowledgments}

The author is thankful to the Director, ICAR Research Complex for North Eastern Hill region, Manipur Centre, Lamphelpat, India, for providing the necessary research facilities.

\section{References}

Aktar, M.W., Sengupta, D., and Chowdhury, A. 2009. Impact of pesticides use in agriculture: their benefits and hazards. Interdiscip. Toxicol. 2(1): 1-12.

Arora, R., and Dhaliwal, G.S. 1996. Agroecological changes and insect pest problems in Indian agriculture. Indian J. Ecol. 23:109-122.

Barrion, J.R.C., Barrion, A.T., and Sebastian, L.S. 2007. Systematics of the Philippines rice black bug Scotinophora Stall (Hemiptera: Pentatomidae). In
Rice black bugs: Taxonomy, ecology and management of invasive spp., Philippine Rice Research Institute, pp 3. Barwal, R.N., Yein, B.R., Roy, S., and Azad, Thakur N.S. 1994. Rice pest: Their status and management in the north Eastern region of India. Indian J. Hill Farm. 7(2): 183-190.

Behura, N., Sen, P., and Kar, M.K. 2011. Introgression of yellow stem borer (Scirphophaga oryzae) resistance gene, into cultivated rice (Oryza sp.) from wild spp. Indian J. Agric. Sci. 81: 359362.

Jenita, Th., Ray, D.C., Singh, K.I., Singh, S.S., and Rocky, Th. 2016. Study of the insect pest complex of rainfed rice cropecosystem of Manipur valley, India. Intern. J. Curr. Res. Acad. Rev. 4(4): 44-50.

\section{How to cite this article:}

Romila Akoijam, Arati Ningombam, Aruna Beemrote and Telem, R.S. 2018. Development of Modified QuEChERS Methodology Coupled with RP-HPLC for Quantification of Various Insecticides in Rice Grains. Int.J.Curr.Microbiol.App.Sci. 7(11): 3030-3035. doi: https://doi.org/10.20546/ijcmas.2018.711.347 